\title{
Knowledge-base for interpretation of cerebrospinal fluid data patterns. Essentials in neurology and psychiatry
}

\author{
Bases do conhecimento para interpretação de padrões de dados em líquido \\ cefalorraquidiano. Essenciais em neurologia e psiquiatria
}

Hansotto Reiber ${ }^{1,2}$

\begin{abstract}
The physiological and biophysical knowledge base for interpretations of cerebrospinal fluid (CSF) data and reference ranges are essential for the clinical pathologist and neurochemist. With the popular description of the CSF flow dependent barrier function, the dynamics and concentration gradients of blood-derived, brain-derived and leptomeningeal proteins in CSF or the specificity-independent functions of B-lymphocytes in brain also the neurologist, psychiatrist, neurosurgeon as well as the neuropharmacologist may find essentials for diagnosis, research or development of therapies. This review may help to replace the outdated ideas like "leakage" models of the barriers, linear immunoglobulin Index Interpretations or CSF electrophoresis. Calculations, Interpretations and analytical pitfalls are described for albumin quotients, quantitation of immunoglobulin synthesis in Reibergrams, oligoclonal IgG, IgM analysis, the polyspecific ( MRZ- ) antibody reaction, the statistical treatment of CSF data and general quality assessment in the CSF laboratory. The diagnostic relevance is documented in an accompaning review.
\end{abstract}

Keywords: cerebrospinal fluid; reference values; immunoglobulin; albumins.

\section{RESUMO}

As bases do conhecimento biológico e biofísico para interpretação de dados do líquido cefalorraquidiano (LCR), assim como das faixas de referência, são essenciais para o patologista clínico e para o neuroquímico. Com a descrição popular da função de barreira dependente do fluxo LCR, a dinâmica e os gradientes de concentração das proteínas derivadas do sangue, do cérebro e da leptomeninge no LCR, bem como as funções específico-independentes dos linfócitos B no cérebro também podem ser essenciais para o diagnóstico ou o desenvolvimento de terapias pelo neurologista, psiquiatra, neurocirurgião e neurofarmacologista. Essa revisão pode auxiliar na substituição de conceitos ultrapassados como os dos modelos de "ruptura" das barreiras, das interpretações lineares do índice de imunoglobulina ou da eletroforese do LCR. Cálculos, interpretações e armadilhas analíticas são descritos para quocientes de albumina, quantificação da síntese de imunoglobulinas em Reibergramas, IgG oligoclonal, análise de IgM, reação MRZ (anticorpo poliespecífico), tratamento estatístico de dados do LCR e qualidade geral das análises no laboratório de LCR. A relevância do diagnóstico está documentada em uma revisão anexa a este documento.

Palavras-chave: líquido cefalorraquidiano; valores de referência; imunoglobulinas; albumin.

The accompaning review ${ }^{1}$ shows, that the conceptual approach to cerebrospinal fluid (CSF) analysis ${ }^{2,3,4,5}$ can provide information about many acute and chronic inflammatory, parasitic, oncological or haemorrhagic pathological processes in the brain neither provided by established electrophysiology nor by actual brain imaging techniques. This emphasizes the demand to perform CSF analysis with the highest possible quality. This is not only a demand for analytical accuracy and precision. The recognition of disease-related data patterns is additionally a challenge for a knowledge-based interpretation ${ }^{1,7}$.
This review provides the physiological and biophysical knowledge base of CSF data interpretation ${ }^{1}$ together with reference values and comments for the analytical aspects ${ }^{6}$ as well as for common pitfalls in the interpretation of the corresponding analytes.

In the worldwide practice of CSF analysis, outdated methods like CSF electrophoresis, linear IgG Index, eventually chlorine ( $\mathrm{CL}^{-}$), Na and $\mathrm{K}$ in CSF are still in use, decades after the appearance of better, scientifically founded and more relevant analytes. The interpretation of increased serum protein 
concentrations in CSF, the so called blood CSF barrier dysfunction, is still most frequently explained by the leakage model of the barrier, with terms like barrier impairment or barrier breakdown. But to understand an increased serum protein concentration in CSF as a functional consequence of reduced CSF flow rate instead of expecting a morphological "leakage" is crucial in neurology, psychiatry as well as in neurosurgery or neuropharmacology. This means that the awareness for the knowledge base of CSF data interpretation is an essential for the clinician in neurology or psychiatry as well as for the clinical neuropathologist or neurochemist.

If neurologists or psychiatrists do not ask for diagnostically relevant analytes who else would do it?

In many countries neuroimmaging is favored over CSF analysis. But the complete immunoglobulin class analysis (IgG, IgA, IgM) with disease-related patterns can provide an earlier and safer diagnosis $^{1}$ and it is also the base for a general quality assessment in the CSF laboratory. The knowledge about the different dynamics of blood- and brain-derived molecules or leptomeningeal proteins in $\mathrm{CSF}^{8,9,10}$ supports basic research allowing to identify the source of molecules in $\mathrm{CSF}^{11,12}$ or provides a new perspective for fast localization of the paracytes in tropical diseases ${ }^{1}$.

The polyspecific antibody synthesis in the brain of multiple sclerosis (MS) patients is the reason for a half century of naive pathophysiological models which expect the condition in brain to represent systemic immunology with a classic antigen/ antibody system. Only the sophisticated evaluation of the knowledge base including immigration of B lymphocytes into brain allows a different view ${ }^{13}$.

As further contributions in this review I regard: the widespread glucose analysis in CSF and combined blood could be beneficially replaced by sole lactate analysis in CSF.

There are only very few clinical studies or research reports with an adequate statistics approach for CSF data, in particular if CSF/serum quotients are involved. A free software can change the avoidance strategies.

Finally it may be encouraging for authorities in external quality control systems in the international frame to adopt the knowledge based interpretation system of INSTAND ${ }^{3}$ extending the solely numerical data control to a general quality assessment.

Particular considerations about the most relevant IgM analysis in $\mathrm{CSF}^{1}$ should help to solve evident analytical problems and sharpen the awareness of the clinicians about the interlaboratory analytical variability.

\section{Blood-derived proteins in CSF}

The concentration of blood-derived proteins in CSF is the consequence of passive, molecular size-dependent diffusion (Table 1), modulated by the individually variable CSF flow rate $^{8}$ (Figure 1).

With a pathologically reduced CSF flow rate ("blood CSF barrier dysfunction") serum protein concentrations increase in brain and CSF. This process has two subsequent influences: after a primary increase of the serum proteins in CSF, e.g., by a reduced CSF outflow along the spinal roots in a Guillain-Barré syndrome (GBS), the concentration in the tissue also follows with an increase (in Figure 2 from normal steady state at A to the steady state in B). This means that the local concentration gradient $\mathrm{dc} / \mathrm{dx}$ at the border between tissue and CSF space is increasing as well. This increased gradient leads to a larger net diffusion into CSF and a further increase of the serum protein concentration in CSF (state C) and so forth.

This process is like a biophysical feed forward mechanism, i.e., the change with increasing CSF concentration (reduced CSF flow rate) results in a nonlinear increase up to a maximal value of $\mathrm{QAlb}=500 \times 10^{-3}$ (= $50 \%$ of blood concentration) and is then decreasing again. This consequence of Fick's second law of diffusion is shown in Figure 2. As a consequence of this nonlinear function of $\mathrm{dc} / \mathrm{dxdt}$ with increasing $\mathrm{c}$, the concentration relation between two molecules (e.g., QIgG:QAlb) follows a hyperbolic function. This hyperbolic function ${ }^{8}$ depends only on the diffusion coefficients of the both molecules $\left(\mathrm{D}_{\mathrm{IgG}} \text { and } \mathrm{D}_{\mathrm{Alb}}\right)^{8}$. From this molecular diffusion /CSF flow model ${ }^{8}$ we learn that in case of a "blood CSF barrier dysfunction" the reduced CSF flow rate is the only change necessary to explain quantitatively the increased concentration of serum proteins in CSF. As expected from the mathematical function ${ }^{8}$ up to the highest concentrations of serum proteins in CSF the passage between blood and brain or CSF remains a diffusion controlled process. This is shown by the symmetry in the reference range around the Qmean in Figure 3 and by the constant biological variation (CV) of the individual parameter in Table 1, which remains constant for all values of QAlb up to the largest Qalb values ${ }^{8}$. As shown in Table 1 and

Table 1. Serum proteins in normal serum and normal CSF. The concentration gradient CSF: serum (CSF:S) depends on the mean molecular radius, $\mathrm{R}$, corresponding only roughly with molecular weight, MW. Mean concentration values given for IgG, IgA and IgM for the mean $\mathrm{QAlb}=5 \times 10^{-3}$ are calculated from Qmean in Ref ${ }^{8}$. The biological variation (CV) of CSF concentration values, analysed in a group of $\mathrm{N}=300$ control patients, are critically dependent on molecular size (diffusion). Serum concentration ranges are the $5^{\text {th }}$ and $95^{\text {th }}$ percentiles ${ }^{3}$.

\begin{tabular}{lcccccc}
\hline \multirow{2}{*}{ Variable } & MW $(\mathrm{kD})$ & $\mathrm{R}(\mathrm{nm})$ & CSF:S & Serum & \multicolumn{2}{c}{ CSF } \\
\cline { 4 - 7 } & & & Mean & Range $(\mathrm{g} / \mathrm{l})$ & median $(\mathrm{mg} / \mathrm{l})$ & $\mathrm{CV}(\%)$ \\
\hline Alb & 69 & 3.58 & $1: 200$ & $35-55$ & 250 & 45 \\
IgG & 150 & 5.34 & $1: 429$ & $7-16$ & 26 & 68 \\
IgA & 160 & 5.68 & $1: 775$ & $0,7-4,5$ & 3,3 & 70 \\
IgM & 971 & 12.1 & $1: 3300$ & $0,4-2,6$ & 0,44 & 105 \\
\hline
\end{tabular}




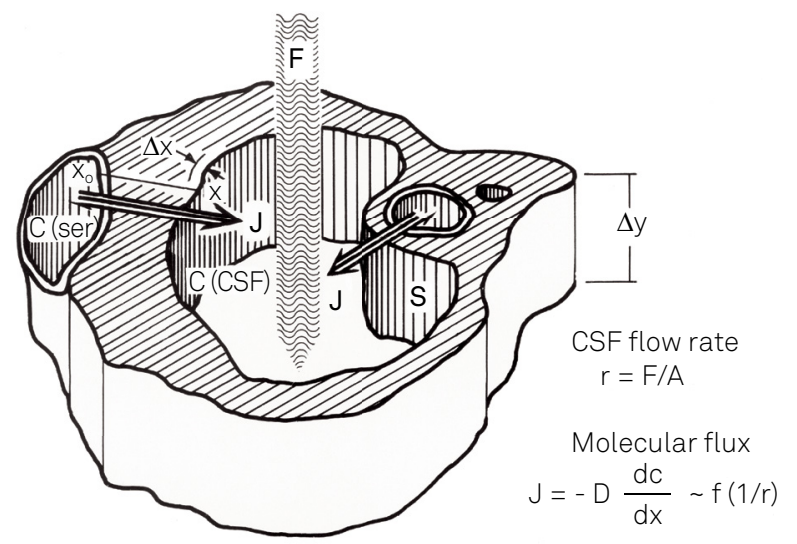

Figure 1. Idealized cross section through the subarachnoidal lumbar space with associated blood vessels. $F=$ bulk flow of CSF with all contents (proteins, cells). The turnover rate $\mathrm{F}$ is about $500 \mathrm{ml} /$ day, in the cisterns divided into lumbar and cortical subarachnoidal space. The local CSF flow rate, $r$, depends on the local cross section, A, of the CSF space. $\mathrm{J}=$ molecular flux (molecular diffusion) according to Fick's $1^{\text {st }}$ law of diffusion depending on the local concentration gradient $\mathrm{dc} / \mathrm{dx}$ and the molecular size dependent diffusion coefficient, D. The overall concentration gradient between blood $\left(\mathrm{C}_{\text {ser }}\right)$ and $\mathrm{CSF}\left(\mathrm{C}_{\mathrm{CSF}}\right)$ is not relevant for the calculation of the molecular flux J. Under pathological conditions with changing CSF flow rate the steady state condition changes into a nonlinear function for $\mathrm{J}$ with dc/ $\mathrm{dxdt}$ corresponding to Ficks $2^{\text {nd }}$ law ${ }^{8}$.

Figure 4 the CV is larger for larger molecular size, following again the laws of diffusion ${ }^{8}$. These data are a sufficient prove that there is no leakage which would change the CV and would have a linear instead of the empirically correct hyperbolic relation between the quotients (QIgG:QAlb) ${ }^{8}$.

\section{Hyperbolic reference range}

The molecular diffusion/CSF flow theory ${ }^{8,9}$ solves the oldest challenge in CSF analysis, the sensitive identification of a brain-derived pathological protein fraction (e.g. intrathecal $\mathrm{IgG}$ ) besides the blood-derived fraction of this protein in total CSF concentration. After many linear approaches, some still in use nowadays (IgG Index), the theoretically founded nonlinear, hyperbolic function provides the base for the reference range of serum proteins in CSF with reference to QAlb (Reibergrams).

The applicable version of the hyperbolic function ${ }^{8}$, e.g., between QIgG and QAlb is of the form:

$\mathrm{QIgG}=\mathrm{a} / \mathrm{b} \sqrt{ }\left(\mathrm{QAlb}^{2}+\mathrm{b}^{2}\right)-\mathrm{c}$ with empirical values for $\mathrm{a}, \mathrm{b}, \mathrm{c}^{3,8}$. These functions for IgG, IgA, IgM are shown in Figures 3 and 4 with upper (Qlim) mean and lower hyperbolic functions of the reference ranges.

\section{The Blood-CSF barrier dysfunction means decreased CSF flow rate}

The increased QAlb should not be misinterpreted as a "leakage" of the blood brain barrier. But it is important to discriminate between the morphologically defined blood-brain barrier and the above functionally defined blood-CSF barrier function.

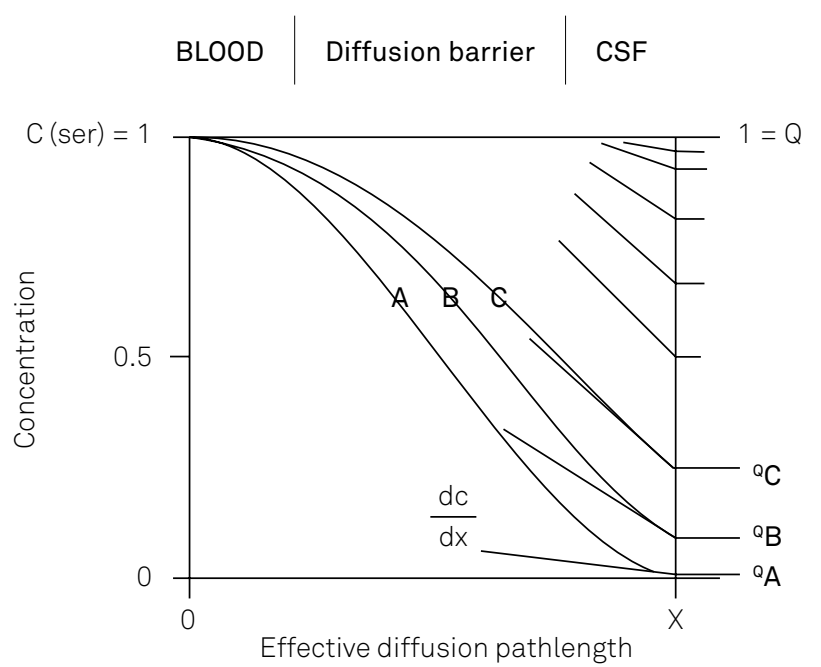

Figure 2. The idealized model of the diffusion between blood and CSF. In blood the mean concentration of a single protein is defined as $\mathrm{C}($ ser $)=1$. In CSF the concentration is given as the CSF/serum quotient ( $Q$ ), a dimensionless concentration of CSF (normalized for the serum concentration). $X$ = the effective diffusion pathlength in the inhomogeneous tissue between blood and CSF. This must not be characterized for the relation of diffusion between two molecules (e.g., albumin and lgM) as this local diffusion path is the same for all serum proteins (e.g., albumin and lgM). The example shows the subsequent changes of the local gradient $\mathrm{dc} / \mathrm{d} x$ with an increasing CSF concentration (e.g. QlgM) increasing from the initial normal QA via QB , QC etc. This time dependent dynamic is the change to Fick's $2^{\text {nd }}$ law with dc/dxdt. The local gradient increases nonlinearly up to a maximum for $\mathrm{QAlb}=500 \times 10^{-3}=0.5$ and subsequently decreases to reach a value $\mathrm{dc} / \mathrm{dx}=0$ for a flow rate $=0$ (e.g. in a corpse). The curve of the nonlinear concentration gradient in the tissue is part of a Gaussian distribution curve ${ }^{8}$.

The actual concentration of serum proteins in CSF is a balance between diffusion into CSF and their elimination by CSF flow. This has many concequences:

1) The albumin quotient, QAlb, becomes a reciprocal

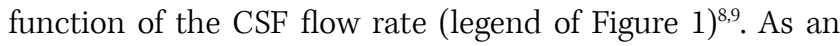
extreme case, after complete stop of CSF circulation in a corpse, the CSF concentration equals the blood concentration $\left(\mathrm{QAlb}=1000 \times 10^{-3}=1\right.$ in Figure 2).

2) Due to the steady diffusion of proteins into CSF along the subarachnoidal flow way the albumin concentration increases 2.5 fold along the rostro-caudal concentration gradient between ventricles and lumbar CSF. The different reference ranges of QAlb in ventricular, cisternal and lumbar CSF have to be taken into consideration. This means also that with increasing extraction volume in lumbar puncture the serum protein concentrations are decreasing.

3) Above a spinal blockage the CSF protein concentrations may be normal but below the blockage the serum proteins are increased but vice versa the concentrations of brain-derived proteins are decreased ${ }^{9,10}$.

4) In newborn children with a low CSF flow rate we get high concentrations of serum proteins in CSF, as indicated with the high QAlb in Table 2. This is a consequence of the immature arachnoid villi which around birth still restrict the 
CSF turnover ${ }^{3}$. The fast maturation in the first 4 months of life with the highest CSF flow rate during the human life time leads to the lowest QAlb values (Table 2).

5) In older age, due to a decreasing CSF production rate in the choroid plexus the QAlb (with all other serum proteins) is increasing slowly (mathematical function for age related reference range, s. below).

\section{Pathophysiology of reduced CSF flow rate}

A reduced CSF turnover may be due to a lumbar blockage by a local tumor or complete disc prolaps, a local inflammation in the lumbar space, a meningeal carcinosis or a blockage of the arachnoid villi outlet by protein complexes or sticking meninges (bacterial meningitis) as well as by a blockage of the CSF outflow along the spinal roots (polyradiculitis Guillain Barré). A reduced CSF production rate (medical treatments) may also reduce the CSF turnover ${ }^{8}$.

\section{Brain-derived and leptomeningeal proteins}

$20 \%$ of the proteins in normal CSF are brain-derived ${ }^{14}$. Proteins which are exclusively synthesized in brain are rare

Table 2. Reference ranges of the albumin quotient of newborns and young children ${ }^{3}$. QAlb is decreasing with increasing CSF flow due to the maturation of the arachnoid villi in the first 4 months.

\begin{tabular}{lccccc}
\hline Age & Birth & 1. Mon & 2. Mon & 3. Mon & 4.Mon to 4 y \\
\hline$Q_{\text {Alb }} \cdot 10^{3}$ & 8 to 28 & 5 to 15 & 3 to 10 & 2 to 5 & 0,5 to 3,5 \\
\hline
\end{tabular}

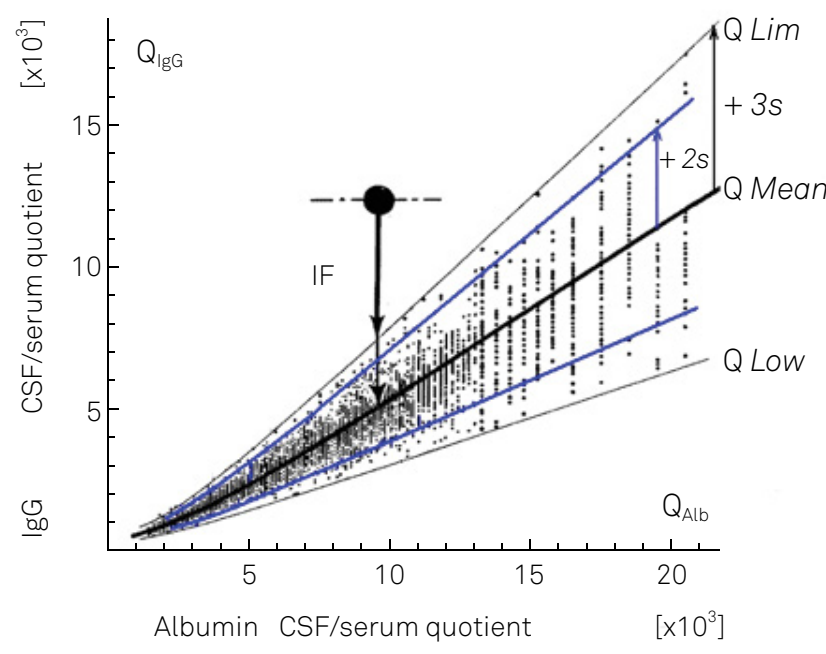

Figure 3. Biological variation of serum proteins in CSF. The reference range of Qmean \pm 3 SD (includes 99\% of the cases) is used for diagnostics and the reference range Qmean \pm 2 SD (includes $96 \%$ of the cases) is used for statistics (s text). The biological coefficient of variation $\mathrm{CV}=\mathrm{SD} / \mathrm{Q}_{\text {mean }} \times 100[\%]$, in this case for IgG in CSF, is constant, i.e. independent of the albumin quotient, QAlb. This indicates a diffusion controlled transfer from blood (no "leakage"). The symmetrical distribution of the values around Qmean support this statement, i.e., the CSF flow rate is the modulator for the barrier function (see Figure 4). but some proteins are predominantly brain-derived with only a minor blood-derived component ${ }^{10}$. The universal validity of the molecular diffusion/CSF flow model ${ }^{8}$, i.e., it is also valid for the brain-derived molecules, is the base for a systematic approach to determine the source of a CSF protein either derived from blood ${ }^{8,9}$, from brain ${ }^{9,10,11}$ or from leptomeninges ${ }^{10,12}$.

Brain-derived proteins which are released into ventricular and cisternal CSF are not modified by CSF flow rate' ${ }^{9}$ They are therefore evaluated by their absolute concentrations in CSF without reference to $\mathrm{QAlb}^{9,10}$. The rostro-caudal concentration gradient is decreasing for brain-derived proteins between ventricular and lumbar CSF. Some of these glial or neuronal proteins reached diagnostic relevance, like Tau protein, $A ß$ amyloid peptides, neuron-specific enolase ( $\gamma \gamma$-dimer) or S100 B protein.

As a basic rule: If the $\mathrm{CV}$ value of a molecule is smaller in CSF of a group of patients than in the corresponding serum of this group the molecule must derive primarily from brain. In case of blood derived molecules in CSF their CV in blood must be higher in CSF by the additional individual variation of CSF flow rate ${ }^{11}$.

The leptomeningeal proteins like beta-trace protein, cytatin $\mathrm{C}$ or mannan-binding lectin $(\mathrm{MBL})^{12}$ are released along the subarachnoidal spinal flow way. Their rostro-caudal concentration gradient is, as expected from the theory, linearly increasing in contrast to the nonlinear gradient for blood derived proteins ${ }^{9,10}$. They are evaluated as absolute CSF concentrations but with reference to QAlb.

In case of a saturation function with increasing QAlb, like that found for s-ICAM ${ }^{10}$, it must be considered that the molecule is interacting with the subarachnoidal environment. This means that the function is not solely diffusion dependent.

The systematic application of this knowledge allowed the finding that neopterin in CSF derives from brain and not from blood ${ }^{11}$ and that the mannan-binding lectin (MBL ${ }^{12}$ in CSF derives from the leptomeninges. A diagnostic application was shown for localization of the different forms of the spinal cord mansonic neuroschistosomiasis ${ }^{1}$.

\section{Small molecules in lumbar CSF}

Changes of small, brain-derived molecules in CSF are not reliably representing brain pathologies as most of them, like cytokines, are metabolized or disappear by reuptake into cells in the interstitial fluid and along the CSF flow way. The exception is neopterin ${ }^{11}$, the endproduct of the tryptophan metabolism, which has no modification between glial cells in brain and lumbar CSF. Its concentration depends only on diffusion and is finally eliminated unmetabolized by the kidneys.

\section{Reference ranges of Qalb and normal barrier functions}

As albumin in CSF originates exclusively from blood, the CSF/serum albumin quotient, QAlb, became the accepted reference value ${ }^{15}$ for the characterization of the blood CSF barrier function and as reference for the evaluation of other blood-derived serum proteins in CSF in quotient diagrams (Figures $3,4,5)^{1}$. 
In contrast to the absolute concentration of the serum protein in CSF the CSF / serum concentration quotient (e.g., QAlb), a dimensionless CSF concentration, allows interpretations independent of the variations in serum (Table 1 and Figure 2) and


Figure 4. Data distribution of patients with an albumin quotient, QAlb, between $20 \times 10^{-3}$ and $150 \times 10^{-3}$ (Part of the data set with 4300 patients) ${ }^{8}$. The upper and lower curve of the reference ranges as well as the curves for the mean $\left(Q_{\text {mean }}\right)$ are hyperbolic functions. The data of the three representative patients are either all (QIgG, QIgA, QIgM) at the upper or lower range or all in a middle range. That means: if one quotient is relatively higher then the other both, this indicates very sensitive an increasing intrathecal synthesis already before the quotient is above the reference range $\left(\mathrm{Q}>\mathrm{Q}\right.$ lim, IF $>0$ ). The ratio $\Delta \mathrm{Q} / \mathrm{Q}_{\text {mean }}$ (corresp. to $\mathrm{CV}$ ) is constant for all QAlb values, but molecular size dependent.

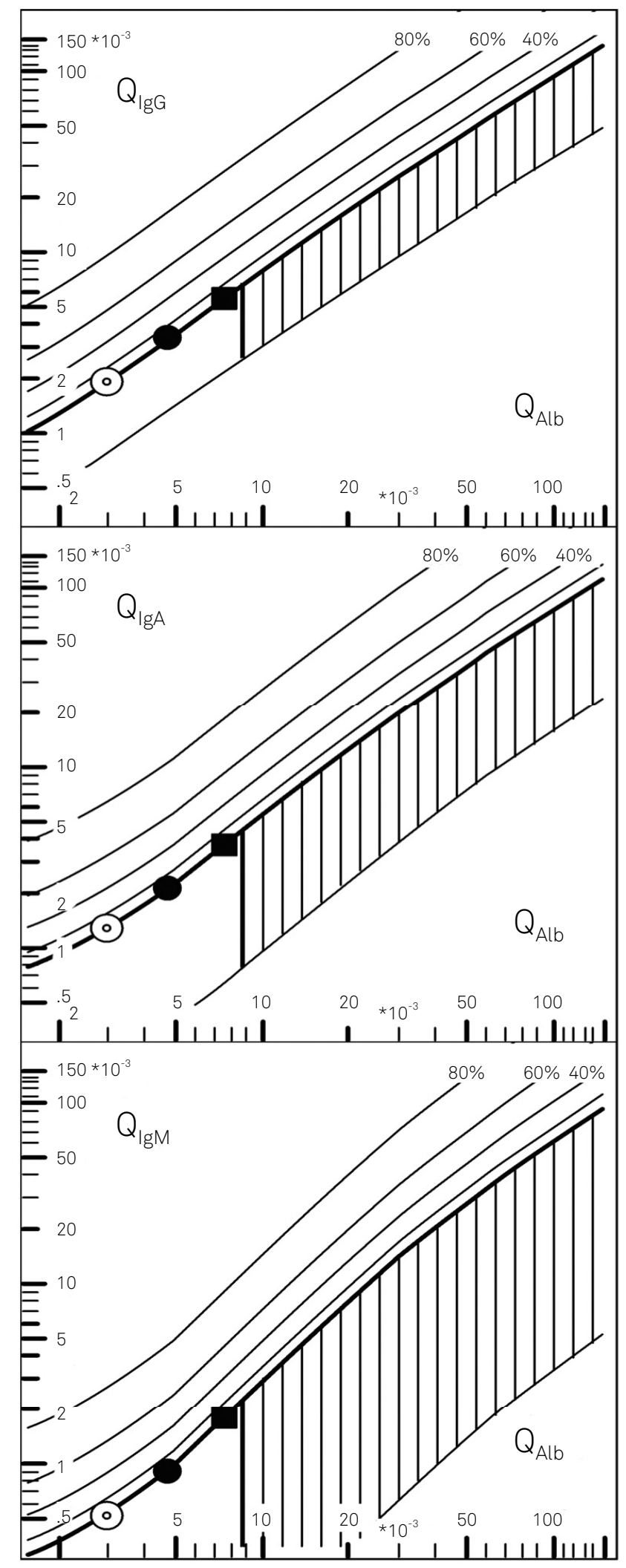

Figure 5. QlgG, QlgA and QlgM values of an individual patient in ventricular (open circle), cisternal (filled circle) and lumbar(square) CSF. The values are in all diagrams on the Qlim curve. Ventricular, cisternal as well as lumbar CSF data can be evaluated in the same quotient diagrams. The shown values of QAlb $(v)=3,0 \times 10^{-3}$, QAlb (c) $=4,8 \times 10^{-3}$ and QAlb $(l)=7,5 \times 10^{-3}$ are normal for an age of $75 \mathrm{y}$. The age-related reference range limits are 3,6 / 6,0 / 9,0 × 10-3 correspondingly (bold vertical bars for the lumbar CSF). This diagram was created with the software from Albaum ${ }^{21}$. 
avoids a possible bias by a systemic immune reaction or barrier dysfunction. This was shown convincingly by our investigations of the African sleeping sickness (s. review ${ }^{1}$ ): The extremely low albumin concentration in blood is cause of a very low albumin value in CSF but it has a normal albumin quotient. The up to twenty-fold increased IgM concentrations in blood cause an increased IgM value in CSF in spite of the absence of an intrathecal IgM fraction in the systemic phase of the disease ${ }^{16}$. Without analysis of serum this is a potential cause of misinterpretation.

It is not acceptable for a reliable CSF analysis to analyse CSF without the paired serum.

But it is not reasonable to calculate CSF / serum quotients for evaluation of brain-derived proteins or low molecular size compounds like interleukins, as this would increase the imprecision, i.e. decrease the sensitivity of discrimination.

\section{Reference ranges of QAlb}

1) The age-dependent reference ranges of the CSF/serum albumin quotient are calculated for adults (including children $>4$ y) with the formula ${ }^{17}$ :

QAlb(ref) $<(4+\operatorname{age}(y) / 15) \times 10^{-3}$.

2) Age-related reference ranges of the albumin quotient of newborn and young children are shown in Table 2.

3) Reference ranges of the albumin quotient in ventricular and cisternal CSF. Due to the rostro-caudal concentration gradient for serum proteins in the CSF space ${ }^{6}$ the reference range of Qalb also differs for ventricular (V-QAlb), cisternal (C-QAlb) and lumbar CSF (Qalb(ref) (Figure 5):

$\mathrm{V}-\mathrm{QAlb}=0.40 \times \mathrm{QAlb}$ (ref);

$\mathrm{C}-\mathrm{QAlb}=0.65 \times \mathrm{QAlb}$ (ref).

Due to the rostro-caudal concentration gradient the interpretation of values around the reference range limits of QAlb should be generous (QAlb (ref) $+10 \%$ for average CSF volumes of $6 \pm 5 \mathrm{~mL}$ extracted). The extent of pathological Qalb is of minor diagnostic relevance, except in the cases of chronic diseases which should have only minor increases (Qalb $<20 \times 10^{-3}$ ).

\section{Immunoglobulins in CSF - Evaluation of intrathecal synthesis}

The immunoglobulin synthesis of the isotypes IgM, IgG or IgA in brain derives from B lymphoctes which immigrate into the brain and synthesize immunoglobulins locally in the perivascular lymphocyte cuffs. The B-lymphocytes immigrate affinity maturated and isotype specific ${ }^{13}$ and their pattern is locally varyingbut rather stable over the initial diagnostic phase of the diseases ${ }^{1}$.

\section{Quantitation of intrathecal immune response}

With the empirical fit from data of 4300 patients the reference ranges for QIgG, QIgA and QIgM in quotient diagrams have been established ${ }^{8}$ (Figures 3 and 4) and the molecular size-related variables a,b,c were determined for quantitative numerical evaluation of intrathecal fractions ${ }^{3,8}$. All possible calculation values in CSF analysis are provided by a suitable free software (www.albaum.it).
The upper limit of the reference range, Qlim, refers to the range which involves $99 \%$ of all patients without an intrathecal Ig synthesis, corresponding to Qmean \pm 3 SD (Figure 3). This upper limit, Qlim, is shown as the bold line in the quotient diagrams (Figure 5$)^{1}$. As a calculation example for IgG we get: $\operatorname{Qlim}(\operatorname{IgG})=\mathrm{a} / \mathrm{b} \sqrt{ }\left(\mathrm{QAlb}^{2}+\mathrm{b}^{2}\right)-\mathrm{c}=0.93 \sqrt{ }\left(\mathrm{QAlb}^{2}+6 \times 10^{-6}\right)$ $-1.7 \times 10^{-3}$

Calculation with QAlb $=5 \times 10^{-3}:$ Q $\lim (\operatorname{IgG})=\left[0.93 \sqrt{ }\left(5^{2}+6\right)\right.$ $-1.7] \times 10^{-3}=3,48 \times 10^{-3}$ and $\operatorname{Qlim}(\operatorname{IgM})=\left[0.67 \sqrt{ }\left(5^{2}+120\right)-7.1\right]$ $\mathrm{x} 10^{-3}=0.968 \times 10^{-3}$

The numerical evaluation of intrathecal synthesis of IgG, IgA or IgM uses two parameters, a) the absolute value of intrathecal, locally synhesized immunoglobulin concentration in CSF, $\operatorname{Ig}_{\text {loc }}$ in $\mathrm{mg} / \mathrm{l}$, and b) its relative intrathecal fraction of the total CSF concentration, $\operatorname{Ig}_{\mathrm{IF}}$ in \%. ${ }^{3,8}$

a) $\operatorname{Ig}_{\text {Loc }}$ - locally synthesized immunoglobulin concentration in CSF:

$\operatorname{IgG}_{\text {loc }}=(\mathrm{Q} \operatorname{IgG}-\mathrm{Q} \lim (\mathrm{IgG})) \times \operatorname{IgG}$ serum $(\mathrm{mg} / \mathrm{L})$

The value for $\operatorname{Ig}_{\text {Loc }}$ does not change with the CSF flow rate $\left(\mathrm{Q}_{\mathrm{Alb}}\right) \cdot \mathrm{Ig}_{\mathrm{Loc}}$ is the best measure for following the dynamics of intrathecal synthesis in the individual patient and is used for calculation of group statistics (below).

b) $\mathrm{Ig}_{\mathrm{IF}}$ - Intrathecal fraction in $\%$ of the total CSF concentration:

$\operatorname{IgG}_{\mathrm{IF}}=$ IgGloc /total CSF IgG x 100 in (\%) or $\operatorname{IgG}_{\mathrm{IF}}=(1-\mathrm{Q} \lim / \mathrm{QIgG}) \times 100(\%)$.

These intrathecal fractions with reference to Qlim (defined as $\operatorname{IgG}_{\mathrm{IF}}=0$ ) can be directly read from the diagrams (percentage lines in Figure 5).

\section{Improvements of sensitivity}

Igloc- and IgIF values $=0$ refer to QLim. So these calculated values represent the minimal amount of intrathecal synthesis which represents the highest diagnostic specificity of the test, but reduces the sensitivity. For higher sensitivity it is possible to refer to Qmean $+2 \mathrm{~s}$ (below) and Qmean (statistics for mean intrathecal synthesis in a group, s. below).

As a quite general determination of an intrathecal immunoglobulin synthesis for QAlb > $1 \times 10^{-3}$ ) we get the following basic (biophysically founded) relations:

Intrathecal IgG synthesis is detected when $\mathrm{Q}_{\mathrm{IgG}}>\mathrm{Q}_{\mathrm{Alb}}$ (in spite $\left.\operatorname{IgG}_{\mathrm{IF}}=0 \%\right)$;

Intrathecal IgA synthesis is detected when $\mathrm{Q}_{\mathrm{IgA}}>\mathrm{Q}_{\mathrm{IgG}}$ (in spite $\left.\operatorname{IgA}_{\mathrm{IF}}=0 \%\right)$;

Intrathecal $\operatorname{IgM}$ synthesis is detected when $\mathrm{Q}_{\mathrm{IgM}}>\mathrm{Q}_{\mathrm{IgA}}$ (in spite $\operatorname{IgM}_{\mathrm{IF}}=0 \%$ ).

Thestillwidespreadused, linear IgGIndex $=\mathrm{QIgG} / \mathrm{QAlb}=0,7$, in particular in cases of increased or low QAlb values provides wrong interpretations ${ }^{4}$.

\section{Dominance of an intrathecally synthesized immunoglobulin class}

The relative value for intrathecal synthesis $\left(\operatorname{Ig}_{\mathrm{IF}}\right)$ takes into account that the amounts of IgG, IgA, and IgM synthesized 
in blood (and in the brain) appear in fundamentally different amounts: under normal conditions there is always more IgG synthesiszed then IgA or IgM. Thus, to compare the intrathecal synthesis of different immunoglobulin classes, this is only possible by calculating the relative values.

Example: With a pattern of $\operatorname{IgM}_{\mathrm{IF}}>\operatorname{IgG}_{\mathrm{IF}}>\operatorname{IgA}_{\mathrm{IF}}$ (three-class reaction), the dominant intrathecal fraction is IgM.

\section{Graphical evaluation in CSF/serum quotient diagrams (Reibergram)}

The graphical evaluation in quotient diagrams ${ }^{4,5}$ has the advantage that the combined diagrams for the $\operatorname{IgG}$, IgA and IgM immune response allow the recognition of disease-related immunoglobulin patterns at one glance. The double logarithmic diagrams (Figure 5 vs Figure 4 with linear axis) emphasize the most relevant normal range and allow best the presentation of the most frequent quotient values in the daily routine (Qalb $<150 \times 10^{-3}$ ). It has to be kept in mind that the Qmean in a logarithmic presentation of the reference range is above the middle (example in $\operatorname{Ref}^{18}$ ).

These diagrams (Reibergram ${ }^{4}$ ) are suitable for interpretation of data from lumbar, cisternal, and ventricular CSF (Figure 5) of patients of all ages including the newborn. This is the consequence of an only from diffusion dependent function. Also the concentration gradient between ventricular and lumbar CSF is not linear9. However, one has to consider the different reference ranges for the albumin quotient (above) for the detection of a so called barrier dysfunction, which in fact is a reduced CSF flow rate.

For the construction of the diagrams as part of the individual CSF data report several professional solutions are available $e^{1,19,20}$. The solution for the individual personal computer is the free software of www.albaum.it ${ }^{21}$. This supplier offers also adaptations to the individual laboratory software. A Portuguese or Spanish version is offered by Arno Wormek (www.wormek.com).

A basic issue of the graphical evaluation is the fact that the data points for the quotients of a normal patient are all in the same relative position in all three diagrams (Figure 4). This allows immediately to recognize a deviation of one of the quotients as a possible beginning of intrathecal synthesis in spite of a value inside the reference range. But such an interpretation depends on a reliable analysis (see IgM below).

The patient with a HIV encephalopathy in Figure 4 of the complementary review ${ }^{1}$ has such a picture for the relatively increased IgG quotient still inside the reference range, confirmed by Oligoclonal IgG bands in CSF.

\section{Antibody detection in CSF - Antibody Index (AI)}

The intrathecally synthesized specific antibodies are detected with parallel CSF and serum antibody analysis and interpretation as Antibody Index.

The linear relation between two quotients is called Index, like IgG Index = QIgG/QAlb or Antibody Index = QAB/QIgG. (QAlb is a quotient not an Index).
The Antibody Index depends on 4 different, independent parameters, i.e., it represents a relative value, e.g., for measles antibodies in subacute sclerosing panencephalitis (SSPE) we get:

$\mathrm{AI}=\mathrm{ABmeasles}(\mathrm{CSF}) / \mathrm{AB}$ measles (serum) $: \operatorname{IgG}(\mathrm{CSF}) / \operatorname{IgG}($ serum)

The AI value does not correspond directly to the amount of intrathecal antibody synthesis and can e.g., increase after treatment, if the normalization of the immune response is faster in blood than in brain. Higher blood values (AB measles(serum)) cause a smaller AI. Low blood antibody concentrations in chronic diseases let the intrathecal synthesis appear with high AI values for measles, rubella, varicella Zoster antibodies (MRZ-AI values ${ }^{22}$ up to AI=50). The quantitative detection of an intrathecal antibody synthesis in CSF needs a different analytical method and evaluation ${ }^{23}$, but has no diagnostic relevance.

The detection of intrathecally synthesized antibodies (Table 3) is most sensitive $\mathrm{e}^{23,24,25}$ with the corrected antibody index ${ }^{26}$ which discriminates two cases:

$\mathrm{AI}=\mathrm{Q}_{\text {spec }} / \mathrm{Q}_{\mathrm{IgG}}$ for $\left(\mathrm{Q}_{\mathrm{IgG}}<\mathrm{Q}_{\mathrm{Lim}}\right)$ and $\mathrm{AI}=\mathrm{Q}_{\text {spec }} / \mathrm{Q}_{\mathrm{Lim}}$ for $\left(\mathrm{Q}_{\mathrm{IgG}}>\mathrm{Q}_{\mathrm{Lim}}\right)$;

$\mathrm{Q}_{\text {spec }}=\mathrm{AB}(\mathrm{CSF}) / \mathrm{AB}($ ser), specific antibody-CSF/serum quotient; $\mathrm{Q}_{\mathrm{Ig}}=\operatorname{IgG}(\mathrm{CSF}) / \mathrm{IgG}(\mathrm{ser})$, empirical immunoglobulin CSF/serum quotient for IgG, IgA or IgM;

$\mathrm{Q}_{\text {Lim }}=$ upper hyperbolic discrimination line of the reference range for blood-derived immunoglobulins (IgG, IgA or IgM).

Clinically determined reference ranges for the Antibody Index, $\mathrm{AI}$, are found to be:

Normal values $\mathrm{AI}=0.6-1.3$;

Intrathecal synthesis $\mathrm{AI} \geq 1.5$.

Values of $\mathrm{AI}<0.5$ are an indication of non-matched $\mathrm{CSF} /$ serum samples or of analytical faults.

In cases where IgG and albumin values are not available, the comparison of the $\mathrm{Q}_{\text {spec }}$ values from different antibody species may suffice. If, e.g., the $\mathrm{Q}_{\text {spec }}$ (measles) is $50 \%$ higher than another $Q_{\text {spec }}$ value, than there is evidence for specific intrathecal synthesis of measles antibodies, independent whether the second species is also increased or not.

\section{Polyspecific MRZ-antibody reaction}

In MS patients, but also in patients with an autoimmune disease with involvement of the brain (Neurolupus, Sjögren syndrome), the intrathecal synthesis of affinity-maturated IgG class antibodies shows a huge variety of antigen specificities $^{13}$. The differences between the direct microorganism-driven immune response (e.g., HIV encephalopathy ${ }^{1}$ or Fuchs' heterochromic cyclitis ${ }^{23}$ ) and the polyspecific immune response (e.g., Multiple sclerosis ${ }^{13}$ ) are shown in Table 4. This polyspecific antibody response is based on earlier systemic infections or immunizations but does neither need the presence or persistence of the causative antigen in the brain nor any other mimicking antigens ${ }^{13}$. The antibody producing B lymphocytes immigrate from blood as antigen-specific, affinity maturated and isotype-specific B cells. A direct comparison 
of antigen-driven rubella antibody synthesis with persistent rubella antigen in the eye $e^{23}$ and the rubella antibody synthesis as part of the MRZ-reaction ${ }^{13}$ can document this observation. A comparison between Aqueous humor and CSF in the individual MS patient shows that the MRZ antibody patterns are arbitrary varying in spite of similar statistical frequencies in both body fluids ${ }^{13}$.

Table 3 shows that the frequencies of polyspecific antibodies in MS patients are between $10 \%$ and $30 \%$ for most of the common antigens, but highest frequencies are observed for measles antibodies (M, up to 80\%), rubella antibodies (R, up to $67 \%$ ) and VZV antibodies (Z, up to 63\%). The combined frequency for one to three of them, with up to $96 \%$ and for the more specific combination of two to three increased AI's in up to $75 \%$ of the MS cases ${ }^{22,24}$ are the reason for their

Table 3. Frequencies of polyspecific antibodies in CSF of multiple sclerosis patients (IgG class). The frequency is different for the different Epstein Barr virus (EBV) antigens $\left(^{*}\right)$ or depends on different prevalence of systemic borrelia infections in different countries, here the different frequencies in Germany and Czech republic $\left(^{* *}\right)^{21}$. The values depend on the use of a corrected Antibody Index ${ }^{22}$ which leads to higher frequencies in particular in MS with a usually high intrathecal total IgG22,23,24,25.

\begin{tabular}{lc}
\hline Antibody specificity & Frequencies in \% \\
\hline Measles (M) & 78 \\
Rubella (R) & 60 \\
Varicella Zoster (Z) & 55 \\
Herpes simplex (H) & 28 \\
Chlamydia & 30 \\
HHV-6 & 20 \\
EBV & $10(30)^{*}$ \\
\hline Borrelia b. & $10-26^{* *}$ \\
toxoplasmosis & 10 \\
ds-DNA & 19 \\
MRZ reaction (2-3 param.) & 75 \\
MRZ reaction (1-3 param.) & 96 \\
\hline
\end{tabular}

Table 4. Differences between IgG class antibodies (AB) from an acute infection with persisting causative antigen and from a polyspecific immune response in the absence of an antigen.

\begin{tabular}{lcc}
\hline Variable & $\begin{array}{c}\text { AB in acute } \\
\text { infection }\end{array}$ & $\begin{array}{c}\text { Polyspecific } \\
\text { AB-Reaction }\end{array}$ \\
\hline $\begin{array}{l}\text { Avidity/Affinity } \\
\text { maturation }\end{array}$ & Low & High \\
Fraction of total CSF IgG & $10-20 \%$ & $0.1-0.5 \%$ \\
Cell count & High & Low $(<20 / \mu \mathrm{l})$ \\
QAlb & High & Low $\left(<15 \times 10^{-3}\right)$ \\
AB concentration & Decaying & Locally Stable \\
Antigen & Present/persisting & Not present \\
Cumulative CSF report & Disease related pattern \\
\hline
\end{tabular}

diagnostic relevance ${ }^{1}$. The individual number of increased AI's depends on the total amount of intrathecal $\operatorname{IgG}^{22}$.

Diagnostically relevant combinations are: MR, RZ, MZ or MRZ. The combination zoster/herpes is not reliable as many Herpes/Zoster caused inflammations have a cosynthesis of the corresponding $\mathrm{H}$ or $\mathrm{Z}$ antibodies. This combination is not a method-dependant artefact but a frequent biological coactivation.

The polyspecific IgG class antibody response in multiple sclerosis $^{13}$ is frequently misinterpreted as a causative part of the pathomechanism ${ }^{27}$. The corresponding intrathecal B cell reaction is better understood as a specificity-independent, selforganizing process ${ }^{13}$.

\section{Oligoclonal IgG}

The qualitative detection of oligoclonal IgG after isoelectric focussing $(\mathrm{IEF})^{6}$ is 50 -fold more sensitive for detection of intrathecal IgG than CSF electrophoresis and still more sensitive than the quantitative IgG analysis. Oligoclonal bands allow the detection of intrathecal IgG with as little as $0.5 \%$ of total CSF IgG, compared to up to $200 \%$ for the difference between lower and upper border of a statistically founded reference range. This sensitivity is the consequence of the low blood-derived IgG fraction in CSF which allows already a small fraction of intrathecal IgG to be recognized. The number of bands in IEF depend on the homogeneity of the $\mathrm{pH}$ gradient and the amount of intrathecal IgG. A single band is not regarded as "oligo"- clonal. Empirically only in 16 of 100 cases this single band in immune detection was associated with an inflammatory process in CNS. Depending on the quality of the $\mathrm{pH}$ gradient and detection method, 2-4 bands (not present in the controls, like the serum of this patient) are regarded as positive for Oligoclonal IgG.

The number and position of the oligoclonal bands are not relevant for the diagnosis.

The parallel focussing of CSF and serum samples allows five standardized interpretations ${ }^{15}$ :

- Type 1: normal;

- Type 2 OCB in CSF, not in serum;

- Type 3 OCB in CSF and Serum, but additional OCB in CSF;

- Type 4 Identical OCB in CSF and serum;

- Type 5: Monoclonal bands in CSF and serum.

Type 2 and 3 indicate an intrathecal synthesis, type 4 a systemic, actual inflammation and type 5 a systemic paraproteinemia. One has to be aware that combinations like type $5+$ type 2 are possible.

Chronic inflammatory diseases have a high frequency of oligoclonal IgG, e.g., up to $98 \%$ in $\mathrm{MS}^{22}$, depending on the quality of the method ${ }^{6}$. In acute inflammatory diseases the appearance of OCB may be delayed like in HSV encephalitis or not detectable like in $50 \%$ of VZV-dependent facial nerve palsies. In these cases the quantitative complete immunoglobulin pattern may give more relevant information ${ }^{1}$. 
OCB is actually still the disease- independent method for the most sensitive detection of an intrathecal IgG class immune response.

Analysis of oligoclonal IgG may be not performed if $\mathrm{Q}_{\mathrm{IgG}}>\mathrm{Q}_{\mathrm{Alb}}$ or QIgG >> Q $\lim (\mathrm{IgG})$. An $\operatorname{IgG}_{\mathrm{IF}}>10 \%$ without OCB has, with reliable methods, a negligible probability.

\section{Cytology and brain hemorrhage}

The cell count of white cells and erythrocytes (RBC) is worldwide the most frequent and established part of every CSF analysis for the basic indication of an inflammatory process or tumors, but also for the detection of an arteficial blood contamination or a brain hemorrhage. The widespread experience with the differential cell counts in cases of inflammatory processes, oncology, paracytology or haemorrhage is extensively described in textbooks with corresponding cell pictures $^{28,29,30}$. Accompaning training programs ${ }^{30}$ and virtual quality control systems for CSF cytology (www.Instand-ev. de) show the still on-going actual relevance of this essential part of CSF analysis.

\section{Hemorrhage or blood contamination in CSF}

The RBC count together with Hemoglobin detection in CSF are an important precondition for a reliable protein data interpretation. The corresponding analytical comments ${ }^{7}$ from cytology in the CSF report could be:

- Total cell count was interpreted by considering the arteficial blood contamination (reduction of 1 leukocyte/ $\mu \mathrm{L}$ per 1000 erythrocytes/ $\mu \mathrm{L}$ in the CSF);

- Quotients are not shown as the values are not reliable due to the large blood contamination (false positive IgM synthesis);

- Correction of CSF albumin and Ig concentrations for blood contamination (in the range of 1000-7000 erythrocytes/ $\mu \mathrm{L}$ ) resulted in $\operatorname{Ig}_{\mathrm{IF}} \leq 0 \%$;

- Despite heavy blood contamination, there is evidence for a humoral immune response: $\mathrm{Q}_{\mathrm{IgG}}>\mathrm{Q}_{\mathrm{Alb}}$ (or $\mathrm{Q}_{\mathrm{IgA}}>\mathrm{Q}_{\mathrm{IgG}}$; or $\left.\mathrm{Q}_{\mathrm{IgM}}>\mathrm{Q}_{\mathrm{IgA}}\right)$.

\section{Antigen detection by PCR}

In cases of an absent or delayed immune response like in HSV encephalitis the polymerase chain reaction (PCR) is the method of choice ${ }^{3}$. But in many diseases the antibody detection is much more sensitive than the detection of the antigen (e.g. only about $<50 \%$ borrelia detection compared to $95 \%$ for borrelia antibodies ${ }^{25}$ ).

\section{Lactate or glucose}

The CSF analysis for lactate or glucose are used for differential diagnosis of a bacterial vs viral cause of an acute meningitis or meningo encephalitis. Lactate has the advantage that only the CSF analysis is necessary (CSF values don't depend on variations of blood lactate concentration due to the saturated lactate transporter). In contrast to lactate, glucose analysis needs the combined CSF and serum values to take into account the fast active transport between blood and CSF. This is e.g., relevant in cases of diabetic patients where the increased CSF glucose value would have the consequence of a false negative interpretation of a pathologically reduced value in CSF. As a further advantage, the pathologically increased lactate values remain longer detectable than decreased glucose concentrations. The normal range of CSF lactate is age dependent.

Pathological values: CSF/Ser (gluc) < 0,45, Lactate $>2,1-2,6 \mathrm{mmol} / \mathrm{l}$. Slightly increased lactate values $(<3,4 \mathrm{mmol} / \mathrm{l})$ are without clinical relevance. Increased lactate values ( $>3,4$ mmole/l) together with the immune response pattern and cell count are of basic differential diagnostic relevance ${ }^{1}$.

\section{IgM analysis in CSF}

Due to the particular relevance of IgM as part of the immunoglobulin synthesis pattern in $\mathrm{CSF}^{1,4}$ its analysis deserves a particular consideration.

IgM analysis in CSF remained notoriously problematic since its invention ${ }^{31}$ due to the low concentrations. The CSF: serum gradient of the large IgM molecule is about 1:3300 compared to 1: 200 for the much smaller albumin (Table 1). $63 \%$ of the normal controls have CSF-IgM concentrations $<0.3 \mathrm{mg} / \mathrm{L}$ with a median of $0.08 \mathrm{mg} / \mathrm{l}$. Only the ELISA reaches a necessary analytical sensitivity for the complete normal range of $\operatorname{IgM}$ in CSF (> 0,005 mg/L). The automated particle amplified nephelometric methods reach a sensitivity of about $0.05 \mathrm{mg} / \mathrm{l}$ (Beckman-Coulter, actual assay since 2014) or 0,15 mg/l (Siemens). The diagnostic relevant concentration values in the daily routine analysis are shown in Table $5.30 \%$ of the IgM concentrations were $<0.2 \mathrm{mg} / \mathrm{l}$, i.e. not reliably measurable.

\section{Comparison of Methods}

The ELISA, used in the 1980ies for IgM analysis was replaced by the more convenient performance in automated nephelometric immunochemical methods, later improved for IgA and IgM by signal amplification with latex particles ${ }^{6}$. The turbidimetric assay ${ }^{6}$ is principally less sensitive than nephelometric assays, but was reinvented recently (Roche) without convincing results for IgM so far.

Table 5. Frequencies of diagnostic relevant concentrations of IgA and IgM in CSF. Data from 8500 consecutively received samples analysed in the Neurochemistry Laboratory, University Göttingen, in 2005-2006.

\begin{tabular}{lccccc}
\hline & \multicolumn{2}{c}{ IgM } & \multicolumn{3}{c}{ IgA } \\
\hline Conc & \multicolumn{2}{c}{ Frequencies } & Conc & \multicolumn{2}{c}{ Frequencies } \\
\hline $\mathrm{mg} / \mathrm{L}$ & $\mathrm{N} / 8467$ & $\%$ & $\mathrm{mg} / \mathrm{L}$ & $\mathrm{N} / 8470$ & $\%$ \\
\hline$<0.2$ & 2,642 & 31.2 & $<0.3$ & 155 & 1.8 \\
$0.2-0.8$ & 3,533 & 41.7 & $0.3-2.0$ & 2,311 & 27.3 \\
$0.8-5.0$ & 1,543 & 18.2 & $2.0-8.0$ & 4,107 & 48.5 \\
$5.0-20$ & 515 & 6.1 & $8.0-20$ & 1,111 & 13.1 \\
$20-100$ & 207 & 2.4 & $20-100$ & 649 & 7.7 \\
$>100$ & 23 & 0.27 & $>100$ & 137 & 1.6 \\
\hline
\end{tabular}


From external quality control of INSTAND ${ }^{32}$, Germany (www.Instand-ev.de), we learned about the discrepancies for CSF IgM analysis between the most frequent nephelometric assays from Beckman Coulter and from Siemens (former Dade Behring).

From theoretical reasons, it is proposed to analyse CSF and serum (diluted) in the same analytical run of the CSF assay to reduce the error propagation in the $\mathrm{CSF} /$ serum quotient for two independent measurements in CSF and serum. But this is only of advantage if the calibration curve fulfills a demand for concentration-independent recovery of serially diluted samples analysed within the same default dilution.

Siemens nephelometry has a problem with up to $100 \%$ variation between calibrations at the lowest calibrator value $(0.15 \mathrm{mg} / \mathrm{L}$ IgM). This is hidden by the mathematical fit of the calibration curve always indicating deviations $<1-3 \%$. Siemens creates additionally a particular problem with the badly matched calibrations between their serum assay and CSF assay. As $40 \%$ of the users analyse serum in the (cheaper) serum assay instead diluted in the CSF assay the results are in some IgM concentration ranges up to $30 \%$ different between both assays of the Siemens group (reports of CSF surveys in www.instand-ev.de).

In contrast to Siemens, Beckman Coulter has reacted on the problems discovered in the CSF surveys (reports in www.INSTAND-eV.de). Their latest improvement made their nephelometric system very sensitive and with a very good interlaboratory accuracy and precission. But the "rate nephelometry" of Beckman ${ }^{6}$, compared to a "two point analysis" of Siemens ${ }^{6}$ needs a strong amplification of the reaction rate, reached by addition of polyethylene glycol. This seems to create a particular problem with variable stabilities of the large IgM molecules in some samples. Eventually the control of bivalent ions in the assay reagents may solve this problem.

A general problem in nephelometric analysis comes from the suppliers badly chosen ranges of default dilutions with a correspondingly high imprecision and unreliable accuracy (variations in the reports from INSTAND surveys with different concentration ranges, see www.instand-ev.de). The nephelometric assays would gain higher reliability, simply by rethinking the suitable concentration ranges for the point of change between default dilutions.

\section{Recommendation for the CSF laboratory and IgM assay suppliers:}

In diagnostically critical cases of low IgM concentrations or low IgM quotients it is proposed to repeat the IgM analysis in CSF and serum with different sample dilutions. The quality of the method in the laboratory can easily be controlled by analysis of a serial diluted serum sample down to the CSF concentrations , measured in between the same default dilution and calculation of the recovery. Comercial contol samples with suitable low concentrations for CSF analysis $(0,2-0,5 \mathrm{mg} / \mathrm{l} \operatorname{IgM})^{15}$ are still missing.

\section{Qualitative IgM in MS}

The successful isoelectric focussing for oligoclonal $\operatorname{IgG}^{6}$ unfortunately can not be applied to IgM analysis as the large pentameric IgM molecule must be dissociated into monomers for the isoelectric focussing in gels. This destroys the concept of a clone-related band as the gel presents agglomerations of IgM monomers fom different clones. This bias leads to the false interpretations in case of barrier dysfunctions with increased blood derived IgM in $\mathrm{CSF}^{33}$.

Also the use of a linear IgM Index is the source of many false interpretations and should be omitted ${ }^{28}$.

\section{Quality assessment system in the CSF laboratory}

The internal and external quality control system for the CSF laboratory was described in detail ${ }^{34}$. The external quality assessment system (EQAS) of INSTAND ${ }^{32}$ takes into account the data interpretation (www.instand-ev.de) analoguous to the knowledge based interpretation of combined CSF data in the CSF report ${ }^{1}$. With this concept we got an extension from the solely control of accuracy for single parameter values to a general quality assessment integrating the interpretation training of the clinical chemist.

The actualization of the parameter spectrum offered by several control institutions will significantly contribute to the quality of CSF analysis by replacing ancient, outdated parameters like chlorine $\left(\mathrm{Cl}^{-}\right)$analysis or CSF electrophoresis.

\section{Statistics and clinical studies with CSF/serum quotients.}

The rare clinical studies and scientific papers which use a correct statistical evaluation of CSF protein data may depend on the missing mathematical experience. A new software program (www.albaum.it) allows the statistical characterization of groups of CSF/serum quotients ${ }^{21}$.

The statistics calculate the mean frequencies of intrathecal synthesis in a group and also the mean quantities of intrathecal synthesis.

Mean frequencies: In contrast to the diagnostic approach for the evaluation of a single patient with reference to the upper limit of the reference range Qlim (Qlim = Qmean +3 SD, corresponding to a $99 \%$ level), the statistical approach for comparison of groups refers to the smaller reference range (Qlim $=$ Qmean +2 SD, corresponding to a 96\% level) as shown in Figure 3. As a consequence we get more reliable interpretations in particular in groups including many patients with a weak intrathecal Ig synthesis. The data for multiple sclerosis patients ${ }^{20}$ can show the relevance: In a group with $98 \%$ positive oligoclonal IgG we find with reference to Qlim = Qmean+3SD only $75 \%$ with IgGloc > 0 , but a frequency with $92 \%$ of pathological IgG in CSF if referred to the lower reference values Qmean+2SD. This was of particular relevance for the evaluation of IgM synthesis in young children with $\mathrm{MS}^{20}$. 
Mean Quantities: The calculation of the mean amount of immunoglobulin synthesized in brain uses the Igloc(mean) with reference to Qmean instead of Igloc with reference to Qlim.

$\operatorname{IgLoc}($ mean $)=[\mathrm{QIg}-\mathrm{Qmean}(\mathrm{Ig})] \times \operatorname{IgSerum}(\mathrm{mg} / \mathrm{L})$.

Such a calculation could be necessary to show the influence of a treatment in a patient group or to proof the null hypothesis for a group without intrathecal synthesis like a group of psychiatric patients ${ }^{18}$. The software of Albaum $^{21}$ offers a corresponding statistics program. To detect the mean of intrathecal synthesis in a group of patients, the program calculates for each patient the individual $\operatorname{Ig}_{\mathrm{loc}}$ (mean) and calculates with these values the mean and $\mathrm{CV}$ of the group.

This calculation takes into account that each patient has a different QAlb with a correspondingly different Qmean for calculation of the $\operatorname{Ig}_{\text {loc }}$ (mean). The free software ${ }^{21}$ offers the data to perform a t-test sufficient to check the Null hypothesis ${ }^{18}$ and calculate significances with p-values. As control data the data set of the 4300 patients, used for the development of the Reibergrams ${ }^{8}$, are integrated in the program ${ }^{21}$.

\section{References}

1. Reiber H. Cerebrospinal fluid data compilation and knowledge-based interpretation of bacterial, viral, parasitic, oncological, chronic inflammatory and demyelinating diseases: diagnostic patterns not to be missed in Neurology and Psychiatry. Arq Neuropsiquiatr. 2016;74(5):336-49. doi:10.1590/0004-282X20160044

2. Machado RL, Livramento JA, Vianna LS. Cerebrospinal fluid analysis in infectious diseases of the nervous system: when to ask, what to ask, what to expect. Arq Neuropsiquiatr. 2013;71(9B):693-8. doi:10.1590/0004-282X20130153

3. Wildemann B, Oschmann P, Reiber H, editors. Laboratory diagnosis in neurology. Stuttgart: Thieme; 2010.

4. Reiber H, Peter JB. Cerebrospinal fluid analysis: disease-related data patterns and evaluation programs. J Neurol Sci. 2001;184(2):101-22. doi:10.1016/S0022-510X(00)00501-3

5. Reiber H. CSF analysis report. In: Wildemann B, Oschmann P, Reiber $H$, editors. Laboratory diagnosis in neurology. Stuttgart: Thieme; 2010. p. 235-48.

6. Reiber H. Principles of analytical methods. In: Wildemann B, Oschmann P, Reiber H, editors. Laboratory diagnosis in neurology. Stuttgart: Thieme; 2010. p. 17-29.

7. Reiber $\mathrm{H}$, Otto M, Trendelenburg C, Wormek A. Reporting cerebrospinal fluid data: knowledge base and interpretation software. Clin Chem Lab Med. 2001;39(4):324-32. doi:10.1515/CCLM.2001.051

8. Reiber H. Flow rate of cerebrospinal fluid (CSF): a concept common to normal blood-CSF barrier function and to dysfunction in neurological diseases. J Neurol Sci. 1994;122(2):189-203. doi:10.1016/0022-510X(94)90298-4

9. Reiber H. Proteins in cerebrospinal fluid and blood: barriers, CSF flow rate and source-related dynamics. Restor Neurol Neurosci. 2003;21(3-4):79-96.

10. Reiber H. Dynamics of brain-derived proteins in cerebrospinal fluid. Clin Chim Acta. 2001;310(2):173-86. doi:10.1016/S0009-8981(01)00573-3

11. Kuehne LK, Reiber H, Bechter K, Hagberg L, Fuchs D. Cerebrospinal fluid neopterin is brain-derived and not associated with blood-CSF barrier dysfunction in non-inflammatory affective and schizophrenic spectrum disorders. J Psychiatr Res. 2013;47(10):1417-22. doi:10.1016/j.jpsychires.2013.05.027

12. Reiber H, Padilla-Docal B, Jensenius J, Dorta-Contreras AJ. Mannan-binding lectin in cerebrospinal fluid: a leptomeningeal protein. Fluids Barriers CNS. 2012;9(1):17-24. doi:10.1186/2045-8118-9-17

13. Reiber H, Kruse-Sauter H, Quentin CD. Antibody patterns vary arbitrarily between cerebrospinal fluid and aqueous humor of the individual multiple sclerosis patient: specificity-independent pathological B cell function. J Neuroimmunol. 2015;278:247-54. doi:10.1016/j.jneuroim.2014.11.013

14. Thompson EJ, editor. The CSF proteins: a biochemical approach. 2nd ed. Amsterdam: Elsevier; 2005.

15. Andersson M, Alvarez-Cermeño J, Bernardi G, Cogato I, Fredman P, Frederiksen $\mathrm{J}$ et al. Cerebrospinal fluid in the diagnosis of multiple sclerosis: a consensus report. J Neurol Neurosurg Psychiatry. 1994;57(8):897-902. doi:10.1136/jnnp.57.8.897

16. Lejon V, Reiber H, Legros D, Djé N, Magnus E, Wouters I et al. Intrathecal immune response pattern for improved diagnosis of central nervous system involvement in trypanosomiasis. J Infect Dis. 2003;187(9):1475-83. doi:10.1086/374645

17. Faber R, Trendelenburg C. Interpretation of CSF quantities with the knowledge-based system Pro.M.D.cerebrospinal fluid diagnostics. J Lab Med. 1997;21(5):257-82. doi:10.1515/labm.1997.21.5.275

18. Bechter K, Reiber H, Herzog S, Fuchs D, Tumani H, Maxeiner HG. Cerebrospinal fluid analysis in affective and schizophrenic spectrum disorders: identification of subgroups with immune responses and blood-CSF barrier dysfunction. J Psychiatr Res. 2010;44(5):321-30. doi:10.1016/j.jpsychires.2009.08.008

19. Regeniter A, Kuhle J, Mehling M, Möller H, Wurster U, Freidank $\mathrm{H}$ et al. A modern approach to CSF analysis: pathophysiology, clinical application, proof of concept and laboratory reporting. Clin Neurol Neurosurg. 2009;111(4):313-8. doi:10.1016/j.clineuro.2008.12.004

20. Siemens. Protis sytem. Siemens; 2016 [cited 2016 Jan 2]. Available from: http://www.healthcare.siemens.com/diagnostics-it/decisionsupport/protis-system

21. Reiber H. Albaum,W. Statistical evaluation of intrathecal protein synthesis in CSF/Serum quotient diagrams. Acta Neuropsychiatr. 2008;20(suppl 1):48-9.

22. Reiber H, Ungefehr St, Jacobi Chr. The intrathecal, polyspecific and oligoclonal immune response in multiple sclerosis. Mult Scler. 1998;4(3):111-7. doi:10.1177/135245859800400304

23. Quentin CD, Reiber H. Fuchs heterochromic cyclitis: rubella virus antibodies and genome in aqueous humor. Amer $\mathrm{J}$ Ophthalmol. 2004;138(1):46-54. doi 10.1016/j.ajo.2004.02.055

24. Reiber H, Teut M, Pohl D, Rostasy KM, Hanefeld F. Paediatric and adult multiple sclerosis: age related differences and time course of the neuroimmunological response in cerebrospinal fluid. Mult Scler. 2009;15(12):1466-80. doi:10.1177/1352458509348418

25. Reiber H, Ressel Chr, Spreer A. Diagnosis of neuroborreliosis-Improved knowledge base for qualified antibody analysis and cerebrospinal fluid data pattern related interpretations. Neurol Psychiatry Brain Res, 2013;19(4):159-69. doi:10.1016/j.npbr.2013.10.004 
26. Reiber H, Lange P. Quantification of virus-specific antibodies in cerebrospinal fluid and serum: sensitive and specific detection of antibody synthesis in brain. Clin Chem. 1991;37(7):1153-60.

27. Olival GS,Lima BM,Sumita LM, SerafimV, FinkMC, Nali LH et al.Multiple sclerosis and herpes virus interaction. Arq Neuropsiquiatr. 2013;71(9B):727-30 doi:10.1590/0004-282X20130160

28. Puccioni-Sohler M, editor. Diagnóstico de neuroinfecção. Rio de Janeiro: Rubio; 2008.

29. Costa Neto JC, editor. Liquido cefalorraquiano. Campo Grande: Life; 2013

30. Kluge H, Wieczorek E, Linke E, Zimmermann K, Isenmann S, Witte OW. Atlas of CSF cytology: with an interactive training course (CD-ROM). Stuttgart:Thieme; 2007 .
31. Sindic CJ, Cambiaso CL, Depre EC, Laterre EC, Masson $\mathrm{PL}$. The concentration of of IgM in cerebrospinal fluid of neurological patients. J Neurol Sci. 1982;55(3):339-50. doi:10.1016/0022-510X(82)90131-9

32. Reiber H. Quality assessment in the CSF laboratory. In: Wildemann $\mathrm{B}$, Oschmann P, Reiber H, editors. Laboratory diagnosis in neurology. Stuttgart:Thieme; 2010. p. 249-53.

33. Reiber H, Rostasy K. Quantitative and qualitative IgM analysis in CSF. Letter response. Mult Scler. 2012;18(2):252-3. doi:10.1177/1352458511418144

34. Reiber H. External quality assessment in clinical neurochemistry: survey of analysis for cerebrospinal fluid (CSF) proteins based on CSF/serum quotients. Clin Chem. 1995;41(2):256-63. 